\title{
RANCANG BANGUN BUKA TUTUP TEMPAT SAMPAH OTOMATIS BERBASIS ARDUINO
}

\author{
Nabila Oper ${ }^{1}$, Govinda Jibrillah Hasan ${ }^{2}$ \\ ${ }^{1}$ Teknik Informatika, Institut Teknologi dan Bisnis Stikom Ambon \\ ${ }^{2}$ Sistem Informasi, Institut Teknologi dan Bisnis Stikom Ambon \\ email: nabila.093@gmail.com ${ }^{1}$, vindahasan2@gmail.com²
}

\begin{abstract}
Abstrak: Lingkungan merupakan salah satu hal terpenting dalam kehidupan. Lingkungan yang kotor dapat membawa dampak buruk pada manusia, maka penulis merancang tempat sampah otomatis berbasis Arduino. Tempat sampah otomatis ini memerlukan alat yang dibagi menjadi 2 bagian, yaitu hardware dan software. Hardware terdiri dari sensor ultrasonic dan motor servo, sedangkan software yang dibuat menggunakan program Arduino IDE. Dalam penelitian ini penulis menggunakan metode Network Development Life Cycle (NDLC), sehingga proses perancangan dapat terarah dengan baik. Hasil dalam penelitian menunjukkan bahwa apabila objek berada pada jarak $<10 \mathrm{~cm}$ dari tempat sampah maka secara otomatis tempat sampah akan terbuka, dan jika sebaliknya maka tempat sampah akan tertutup
\end{abstract}

Kata Kunci: Arduino, Network Development Life Cycle, sensor ultrasonic, motor servo

Abstract: The environment is one of the most important things in life. A dirty environment can negatively impact humans, so the author designed an Arduino-based automatic trash can. This automatic trash can requires tools that are divided into two parts, namely hardware and software. The hardware consists of ultrasonic sensors and servo motors, while the software is made using the Arduino IDE program. In this study, the author uses the Network Development Life Cycle (NDLC) method so that the design process can be well directed. The results in the study show that if the object is at a distance of $<10 \mathrm{~cm}$ from the trash can, the trash can will automatically open, and if it's the other way around, the trash can will be closed.

Keywords: Arduin, Network Development Life Cycle, ultrasonic sensors, servo motors

\section{PENDAHULUAN}

Teknologi pada masa kini berkembang sangatlah cepat dan dapat dirasakan oleh semua kalangan, dimana teknologi merupakan hasil dari peradaban manusia yang semakin maju. Teknologi yang berkembang saat ini terutama dalam bidang robotika dengan menggunakan mikrokontroller sebagai komponen utamanya. Dengan adanya mikrokontroller, kita dapat merancang dan membangun sebuah alat baik dari segi jaringan, komunikasi, keamanan, maupun lingkungan.

Hapir semua tempat umum seperti pinggiran jalan, bandara, sekolah dan tempat umum lainnya, masih banyak terlihat sampah yang berceceran dimana-mana, dikarenakan tempat sampah yang masih secara manual membuka dan menutup kembali tutup sampah, yang membuat seseorang jadi malas untuk membuang sampah pada tempatnya. Terkait dengan hal tersebut, penulis ingin merancang sebuah tempat sampah otomatis, yang memiliki fitur membuka dan menutup kembali tempat sampah itu sendiri. Tempat sampah yang bersih dengan sentuhan teknologi modern akan membuat daya Tarik masyarakat untuk selalu membuang sampah pada tempatnya.

Dengan adanya tempat sampah otomatis, secara langsung kita sudah mengajarkan masyarakat agar selalu membuang sampah pada tempatnya, dan memberikan mereka sentuhan teknologi dalam membangun sebuah tempat sampah otomatis. Tempat sampah otomatis ini memerlukan alat yang dibagi menjadi 2 bagian, yaitu hardware dan software.
Hardware terdiri dari sensor ultrasonic untuk mendeteksi objek, mikrokontroller sebagai rangkaian pengendali input dan output untuk menggerakkan motor servo, sedangkan software yang dibuat menggunakan program Arduino adalah Bahasa pemograman C (Arduino).

\section{TINJAUAN PUSTAKA}

Penelitian yang dilakukan oleh Kurniawan dan Winarno (2012), yang berjudul "Prototie Pengangkat Sampah Otomatis Pada Saluran Pintu Air Berbasis Mikrokontroler ATmega 8535" penelitian yang dilakukan bertujuan untuk pengangkatan sampah dengan konveyor atau pembawa sampah. Mikrokontroler ATmega 8535 yag digunakan sebagai pengendali input, output, driver motor DC, LCD display dan buzzer, dan hasilnya prototipe pengangkat sampah otomatis pada saluran pintu air kemudian hasil pengangkatan dibawa oleh konveyor. Rangkaian catu daya yang dibutuhkan pada system ini yaitu sebesar 5 volt dan 12 volt. Meski hasil pengukurannya adalah 4,8 volt dan 11.8 volt. Driver motor DC menggunakan driver relay SPDT, DPDT sehingga motor DC dapat menampilkan huruf dengan jelas ketika tegangan kontras 2,7 volt - 3,3 volt, dan tidak ada tampiplan huruf ketika tegangan kontras 2 volt. Buzzer pada Prototipe Pengangkat Sampah Otomatis Pasa Saruran Pintu Air Berbasis Mikrokontro;er ATmega 8535 dapat berbunyi ketika pembukaan pintu air akan bekerja.[3] 
Penelitian yang dilakukan oleh Suradi, Syarifuddin Baco dan Mendiana (2020), yang berjudul "Perancangan Tempat Sampah Pintar Menggunakan Mikrokontroller Berbasis SMS Gateway". Penelitian yang dilakukan bertujuan untuk dapat membuat tempat sampah pintar menggunakan mikrokontroller berbasis SMS gateway, bahan yang digunakan dalam penelitian ini adalah komponen mekanik akrilik $2 \mathrm{~mm}$, sekrup, spacer pendek, engsel mini, lem lilin, karet spont, print circuit board (PCB). Komponen system control board Arduino nano, sensor ultrasonic/SR-04, kabel jumper, motor servo mini, GSM modul sim 900i v.1, bletooth HC-05, batterai 3,7 v, batterai lipo 11.1, regulator 7805, led $3 \mathrm{~mm}$, buzzer, kabel US. Metode yang digunakan secara umum, yaitu metode Research and Development (R\&D). R\&D adalah metode penelitian yang digunakan untuk menghasilkan produk tertentu, dan menguji keefektifan produk tersebut. Cara kerja dari tempat sampah pintar berbasis sms gateway ini, yaitu : pertama-tama sensor jarak HCSR04 akan mendeteksi ada atau tidaknya objek yang berada atau mendekat. Jika objek terdeteksi, maka berikutnya sensor PIR akan bertugas memverifikasi objek tersebut apakah manusia atau bukan. Jika objek tersebut manusia, maka secara otomatis penutup tempat sampah akan terbuka dalam rentang waktu beberapa detik. Setelah itu tempat sampah akan tertutup Kembali. Jika objek yang mendekat terverifikasi oleh sensor PIR adalah bukan manusia, maka penutup tempat sampah akan tetap tertutup. Pada bagian dalam penutup tempat sampah, terdapat sensor jarak infra-merah shrap GP2D12. Sensor ini berfungsi untuk mendeteksi volume sampah. Jika terdeteksi bahwa tempat sampah hampir penuh, maka system akan mengirimkan informasi tersebut ke nomor yang sudah di intergrasikan ke dalam system pengendali. Selama volume sampah terdeteksi hampr penuh, maka secara default system juga akan mengunci penutup tempat sampah untuk menghindari terjadinya overload pada tempat sampah.[12]

Penelitian yang dilakukan oleh Riswanti Singgi (2017), yang berjudul "Rancang Bangun Pembuka Dan Penutup Tempat Sampah Otomatis Berbasis Mikrokontroler", penelitian yang dilakukan bertujuan untuk dapat membuka dan menutup tempat sampah secara otomatis, dengan alat yang digunakan adalah Development Doard Arduino (Arduino Uno), Motor servo, sensor jarak (ultrasonic) dan LED. Jika sensor jarak (ultrasonic) yang pertama menangkap suatu objek di dekat tempat sampah, dengan jarak kurang dari $35 \mathrm{~cm}$ maka mikrikintroler akan mengerakkan motor servo untuk membuka tutup tempat sampah secara otomatik setelah terbuka jika disekitar tempat sampah tidak ada objek yang mengenai sensor maka mikrokontroler akan menggerakkan motor servo untuk menutup tempat sampah Kembali. Sensor jarak (ultrasonic) yang kedua memberi pengaruh pada system tempat sampah otomatis ini yaitu saat sampah yang masuk kedalam kotak sampah mendekati sensor dengan jarak kurang dari $10 \mathrm{~cm}$ maka sensor ini akan memberi perintah pada LED untuk menyala.[9]

\section{Dasar Teori}

Adapun dasar teori yang mendukung dalam pembuatan

\section{a. Arduino IDE (Integrated Development \\ Enviroment)}

Software IDE Arduino adalah pengendali mikro single-board yang bersifat open-source, diturunkan dari platform Wiring. Dirancang untuk memudahkan penggunaan eleltronik dalam berbagai bidang, hardware-nya menggunakan prosesor Atmel AVR dan software-nya memiliki bahasa pemrograman $\mathrm{C}++$ yang sederhana dan fungsifugsinya yang lengkap, sehingga arduiono mudah dipelajari oleh pemula. Komponen-komponen dari Software IDE Arduino memperlihtkan tampilan menu bar yang terdiri dari : File, Menu Edit, Menu Sketch,, Menu Tools, dan Menu Help.[4]

b. Sensor Jarak (Ultrasonic)

Sensor jarak ultrasonic adalah sensor yang bekerja berdasarkan prinsip pantulan gelombang suara yang digunakan untuk mendeteksi keberadaan suatu objek atau benda tertentu dengan meniru kelelawar maupun lumba-lumba. Gelombang yang dipancarkan berfrekuensi $40 \mathrm{KHz}$. Salah satu jenis sensor ini yang sangat popular adalah HC-SR04. Spesifikasi yang diberikan menyatakan bahwa sensor ini mampu mengukur jarak dari $2 \mathrm{~cm}$ hingga $4 \mathrm{~m}$. dalam praktik, sensor hanya mampu mengukur jarak hingga sekitar $3 \mathrm{~m}$ atau malah kurang. Jenis lain yang juga bisa digunakan untuk praktik adalah US-015. [5]

Kedua modul tersebut memiliki susunan pin yang sama. Masing-massing perlu dihubungkan dengan pin-pin di Arduino dengan ketentuan sebagai berikut:

- VCC dihubungkan ke pin 5V miliki Arduino.

- GND dihubungkan ke pin GND milik Arduino.

- Pin Trig dihubungkan ke pin digital milik Arduino, untuk memulai pengiriman sinyal ke objek yang akan diukur.

- pin Echo dihubungkan ke pin digital milik Arduino, yang akan menerima sinyal yang dipantulkan oleh objek yang diukur.

\section{c. Motor Servo}

Motor Servo adalah motor yang juga menggunakan tegangan DC, tetapi mempunyai sifat yang khas, yakni memungkinkan pengaturan ke sudut tertentu. hal ini terjadi pada motor servo yang berputar dari 0 hingga 180 derajat. Motor Servo dapat digunakan untuk membuka pintu, mengatur Gerakan lengan robot, atau membelokkan arah pesawat terbang mainan. Salah satu motor servo SG90 mempunyai tiga kabel. Umumnya, warna 
kabel berupa merah, cokelat, dan oranye. Kabel merah dihubungkan ke sumber tegangan $5 \mathrm{~V}$, kabel cokelat dihubungkan ke ground, dan kabel oranye dihubungkan ke pin digital untuk mengontrol sudut motor. [5]

\section{METODE}

Metode yang digunakan dalam penelitian ini yaitu Network Development Life Cycle (NDLC). Menurut Goldman dan Rawles (2001), Network Development Life Cycle (NDLC) adalah metode yang digunakan untuk pengembangan dan membangun jaringan komputer yang mendefinisikan siklus proses perancangan atau pengembangan suatu sistem jaringan komputer. Tahapan dalam metode NDLC ini yaitu: Analysis (analisis), Design (perancangan), Simulation Prototype (simulasi), Implementation (implementasi), Monitoring dan Management. Berdasarkan penjelasan di atas, maka penulis menggunakan metodologi Network Development Life Cycle (NDLC) pada penelitan penulis saat ini. [15]

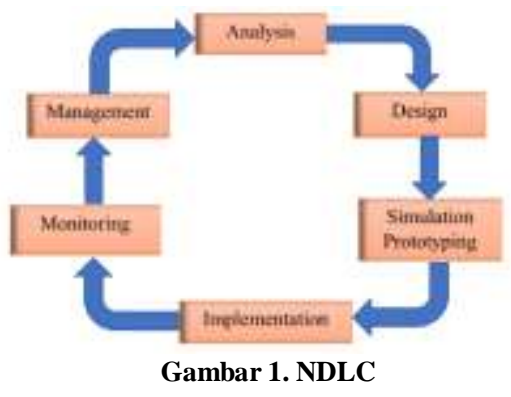

Tahapan Penelitian

Tahapan penelitian mencangkup langkah-langkah pelaksanaan penelitian dari awal sampai akhir. Langkah-langkah tersebut dapat diuraikan pada alur tahapan penelitian sebagai berikut:

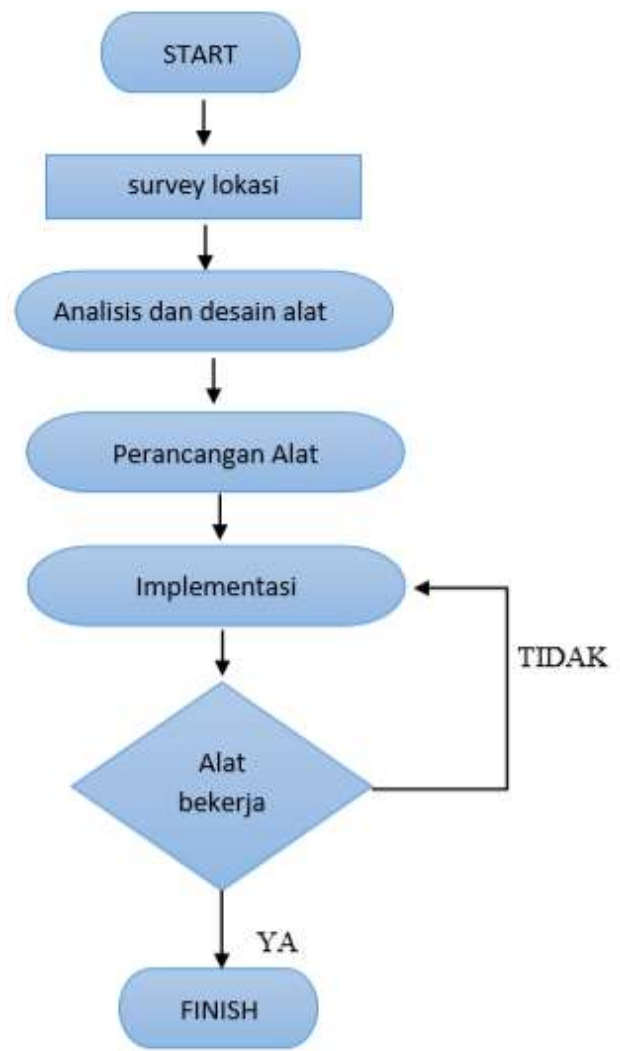

Gambar 2. Alur rancangan yang diusulkan

\section{Teknik Pengumpulan Data}

Terdapat 3 metode pengumpulan data yang digunakan pada penelitian ini, antara lain [3]:

a. Observasi dilakukan dengan melihat secara langsung tampilan aplikasi penjualan

b. wawancara dilakukan pada karyawan atau pengguna aplikasi

c. Kuisioner, pengumpulan data yang dilakukan dengan mengajukan pertanyaan tertulis kepada responden.

\section{HASIL DAN PEMBAHASAN}

\section{Persyaratan Sistem}

Persyaratan sistem pada rancang bangun buka tutup tempat sampah otomatis berbasis Arduino, membutuhkan perangkat keras dan perangkat lunak agar dapat menjalankan sistem dengan baik.

\section{Perangkat Keras (Hardware)}

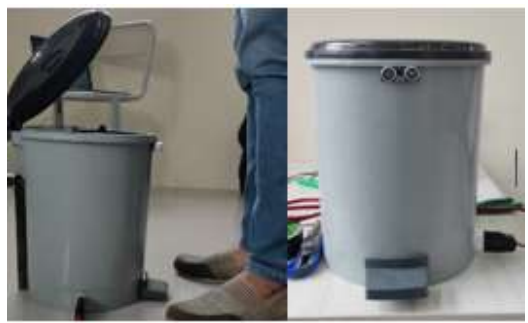




\section{Gambar 3. Perangkat Keras}

Gambar di atas merupakan sebuah tempat sampah otomatis berbasis Arduino yang bisa terbuka dan tertutup secara otomatis, system kerja dari alat ini adalah dengan menggunakan beberapa perangkat yaitu Arduino Uno, Sensor Ultra Sonic, dan Motor Servo. Cara kerja alat ini adalah dengan memasukkan beberapa coding program atau menggunakan software dari Arduino yang di konfigurasi dengan mengatur program untuk Arduino Uno, Motor Servo dan Sensor Ultra Sonic.

\section{Perangkat Lunak (Software)}

Berikut adalah Script program pada penelitian rancang bangun buka tutup tempat sampah berbasis Arduino.

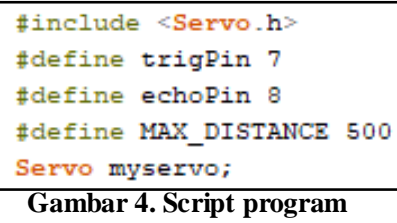

Pada potongan program diatas menunjukkan \#include <Servo.h> adalah library untuk motor servo, \#define trigPin 7 adalah Trigger sensor ultra sonic di Pin digital 7, \#define echoPin 8 adalah Echo sensor ultra sonic di Pin digital 8, \#define MAX_DISTANCE 500 adalah jarak maksimal dan Servo myservo adalah nama untuk 1 buah motor servo.

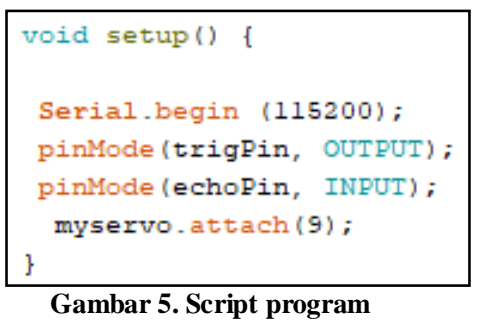

Pada potongan program diatas menunjukkan fungsi yang akan dijalankan hanya satu kali ketika program Arduino mulai dijalankan. Fungsi ini isinya berupa perintah untuk menentukan fungsi pada sebuah pin. Serial.begin (115200); adalah digunakan untuk komunikasi Arduino dan computer, pinMode(trigPin, OUTPUT); adalah set pin Trigger sebagai output, pinMode(echoPin, INPUT); adalah set pin Echo sebagai input, dan myservo.attach(9); adalah set servo pada pin PWM 9.

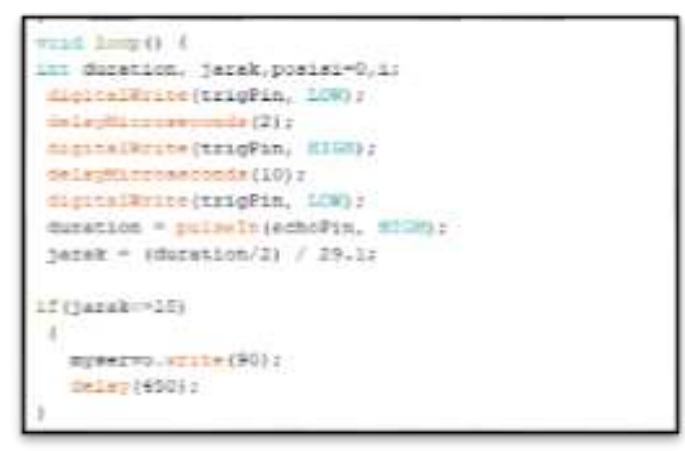

Gambar 6. Script program

Pada potongan program diatas menunjukkan sebuah kondisi, dan jika kondisinya sudah terpenuhi maka akan melaksanakan perintah yang sudah ditentukan. dan saat tidak memenuhi kondisinya juga ada perintah yang dilaksanakan oleh Arduino.

\section{KESIMPULAN}

Setelah dilakukan perancangan, maka kesimpulan yang didapat adalah rancang bangun buka tutup tempat sampah otomatis berbasis Arduino menggunakan 1 sensor ultrasonic, jarak yang diperlukan oleh tempat sampah agar penutup tempat sampah terbuka ketika ada obyek di depan tempat sampah kurang dari $10 \mathrm{~cm}$ maka penutup tempat sampah terbuka. Dan ketika sensor ultrasonic tidak lagi mendeteksi adanya obyek, atau obyek lebih dari $10 \mathrm{~cm}$ maka penutup tempat sampah akan tertutup secara otomatis.

\section{SARAN}

Pada penelitian selanjutnya Hardware yang dibangun dapat dimanfaatkan dan dikembangkan lagi dengan komponen yang mendukung serta penggunaan tempat sampah dapat menggunakan ukuran yang kapasitasnya lebih besar.

\section{DAFTAR PUSTAKA}

[1]Bishop, Judith \& Horspool, Nigel, 2004, C\# Concisely, Addison Wesley, London.

[2] Daniel A. O. Turang. Pengembangan Sistem Relay Pengendalian Dan Penghematan Pemakaian Lampu Berbasis Mobile. Teknik Informatika, Sekolah Tinggi Teknologi Bontang. Seminar Nasional Informatika Yogyakarta 14 November 2015

[3] Kurniawan Abdillah, dan Winarno Heru.(2012). Prototipe Pengangkat Sampah Otomatis Pada Saluran Pintu Air Berbasis Mikrokontroler Atmega 8535. Gema Teknologi., Vol.17 No. 2.

[4] Heri Andrianto dan Aaan Darmawan (2017), "Buku Arduino Belajar Cepat dan Pemrograman". Informatika Bandung, September 2017.

[5] Kadir, A.. 2017. Buku Pemrograman Arduino Menggunakan Ardublock. Yogyakarta : Penerbit Andi.

[6] Mualief Anwar Ismai, Riska K. Abdullah Dan Syahrir Abdussamad (2021). "Tempat Sampah Pintar Berbasis Internet of Things (IoT) Dengan Sistem Teknologi Informasi". Jambura Journal of Electrical and Electronics Engineering (JJEEE), Vol.3 No.1 Januari 2021 
[7] Pressman RS. 2002. Rekayasa Perangkat Lunak. Terjemahan dari Software Engineering. Yogyakarta: Andi 42

[8] Rahmat Sulaiman Naibaho (2017), "Peranan Dan Perencanaan Teknologi Informasi Dalam Perusahaan". Jurnal Warta Edisi :52, Universitas Dharmawangsa.

[9] Riswanti Singgi.(2017). Rancang Bangun Pembuka Dan Penutup Temat Sampah Otomatis Berbasis Mikrokontroler. Jurusan Teknologi Informasi, Politeknik Negeri Samarinda 2017.

[10] Rudi Kurniawa (2016), "Analisis Dan Implementasi Desain Jaringan Hotspot Berbassis Mikrotik Menggunakan Metode NDLC (Network Development Life Cycle) Pada Bpu Bagas Raya Lubuklinggau". STMIK Mura Lubuklinggau, Jurnal Ilmiah Batrik, Vol.07, No.01, April 201643

[11] Setiawan, D., Syahputra, T., \& Iqbal, M. (2014). Rancang Bangun Alat Pembuka Dan Penutup Tong Sampah Otomatis Berbasis Mikrokontroler. Jurnal Teknologi Dan Sistem Informasi, Volume 1, Nomor 1, Desember 2014,Hlm55-62, 1(1), 55-65.

[12] Suradi, Syarifuddin Baco dan Mendiana (2020), "Perancangan Tempat Sampah Pintar Menggunakan Mikrokontroller Berbasis SMS Gateway". Dekan Teknik Universitas Islam Makassar. ILTEK : Jurnal Teknologi, Vol.15 No.02 Oktober 2020.

[13] Susanto, G.. Irwanto R.E., dan Subandi. Bel Sekolah Otomatis berbasis Mikrokontroller ATMEGA8. Jurnal Elektrikal 1: 13-18.

[14] Wiyandra.Y, Yayandri.A, \& Sovia.R.(2013). Aplikasi Tong Sampah Berbicara Berbasis Mikrokontroller Atmega8535 Didukung Bahasa Pemrograman C Dengan Output Suara Dan Seven Segment. Jurnal Teknologi Informasi \& Pendidikan., Vol. 6 No.2, ISSN : $2086-4981$

[15] James E. Goldman and Philip T. Rawles. (2001). Applied Data. Communications A Business-Oriented Approach. Mishawaka, US 